\title{
REACTION TIMES TO NEON, LED, AND FAST INCANDESCENT BRAKE LAMPS
}

\author{
Michael Sivak \\ Michael J. Flannagan \\ Takashi Sato \\ Eric C. Traube \\ Masami Aoki
}

September 1993 


\title{
REACTION TIMES TO NEON, LED, AND FAST INCANDESCENT BRAKE LAMPS
}

\author{
Michael Sivak \\ Michael J. Flannagan \\ Takashi Sato \\ Eric C. Traube \\ Masami Aoki
}

The University of Michigan

Transportation Research Institute

Ann Arbor, Michigan 48109-2150

U.S.A.

Report No. UMTRI-93-37

September 1993 


\begin{abstract}
Standard incandescent brake lamps have a relatively slow rise time. It takes approximately a quarter of a second for them to reach $90 \%$ of asymptotic light output, causing potential delays in responses by following drivers. The present study evaluated reaction times to brake signals from standard incandescent brake lamps and from three alternative brake lamps with substantially faster rise time: neon, LED, and fast incandescent. The study, performed in a laboratory, simulated a daytime driving condition. The subject's task was to respond as quickly as possible to the onset of either of two brake lamps in the visual periphery, while engaged in a central tracking task. Brake signals were presented at two levels of luminous intensity.

The results showed that reaction times to the alternative brake lamps were faster than to the standard incandescent lamp, with the advantage averaging $166 \mathrm{~ms}$ for the LED and neon lamps, and $135 \mathrm{~ms}$ for the fast incandescent lamp. A reduction of the signals' luminous intensity from $42 \mathrm{~cd}$ to $5 \mathrm{~cd}$ increased the reaction time by $84 \mathrm{~ms}$. For the neon, LED, and fast incandescent lamps all at $5 \mathrm{~cd}$, the frequencies of reaction times longer than $1 \mathrm{~s}$ were all similar, and they were comparable to the frequency for the standard incandescent lamp at 42 cd.
\end{abstract}

Key words: brake lamps, stop lamps, brake signals, stop signals, lamp rise time, reaction time, response time 


\title{
ACKNOWLEDGMENTS
}

Appreciation is extended to the members of the University of Michigan Industry Affiliation Program for Human Factors in Transportation Safety for support of this research. The current members of the Affiliation Program are:

\author{
Bosch \\ Carello Lighting \\ Chrysler \\ Donnelly \\ Ford (Plastic and Trim Products Division) \\ GM (Inland Fisher Guide Division) \\ Ichikoh Industries \\ Koito Manufacturing \\ Libbey-Owens-Ford \\ LESCOA \\ Muth Advanced Technologies \\ Osram Sylvania \\ Philips Lighting \\ PPG Industries \\ Stanley Electric \\ $3 \mathrm{M}$
}

Special thanks go to Philips Lighting and Stanley Electric for constructing two of the test lamps used in this study, and to Dennis Battle for his assistance. 


\section{CONTENTS}

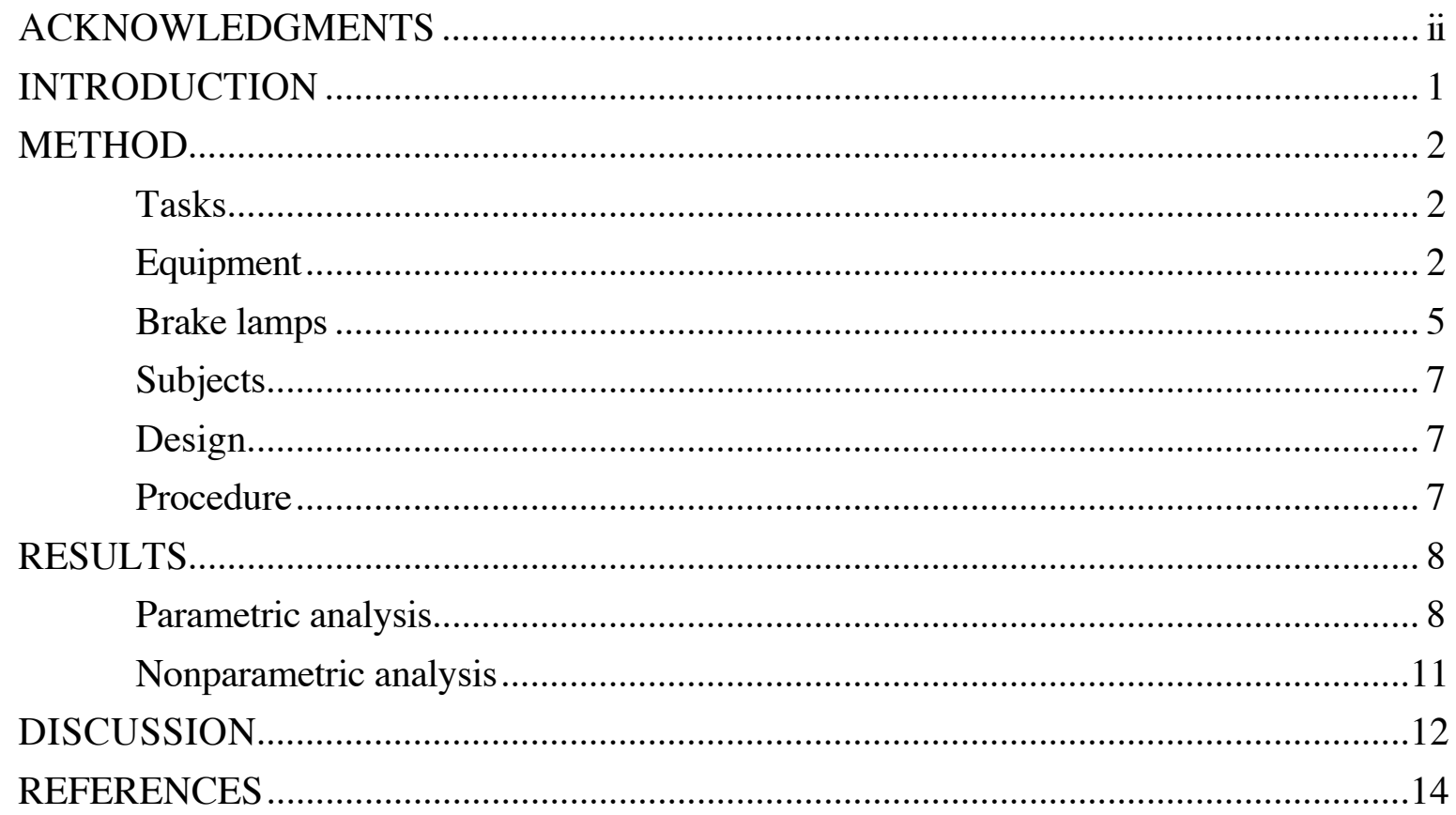




\section{INTRODUCTION}

The time that a driver has to recognize and react to brake signals is often limited. However, despite the importance of brake signals, the standard equipment used to provide them is relatively slow. After the voltage is applied to standard incandescent brake lamps, no measurable light is emitted for about $50 \mathrm{~ms}$, and it takes on the order of a quarter second to reach $90 \%$ of the steady state output (Flannagan and Sivak, 1989; Sivak and Flannagan, 1993).

There are alternatives to standard incandescent brake lamps that have faster rise times. One alternative is to preheat the tungsten filament continuously at low voltage (below visible), coupled with a brief overvoltage at the time of the application of the brakes (Flannagan and Sivak, 1988). Another alternative is to use light sources with inherently faster rise time, such as LEDs or neon. While benefits of LED and fast incandescent lamps have been evaluated (Olson, 1987; Flannagan and Sivak, 1989), we are not aware of any published studies on reaction times to signals from neon lamps. Furthermore, since reaction times to signals are sensitive to a variety of parameters (e.g., subject load, visual angle between the line of sight and the signal, signal intensity and size, ambient illumination), it would be desirable to compare alternative brake lamps under the same conditions.

The present study was designed to compare reaction times to brake signals from four different types of brake lamps: standard incandescent, fast incandescent, LED, and neon. All lamps were tested at two levels of luminous intensity. 


\section{METHOD}

\section{Tasks}

Subjects performed two concurrent tasks. One task was to press a response button as soon as either of two brake lamps was turned on. The lamp was turned off as soon as a response was made, so the subject received immediate feedback. The other task was to control a compensatory tracking task designed to approximate the perceptual and motor workload of driving. The tracking task was a dynamic simulated road scene on a computerdriven monitor. The subject's task was to keep the road centered on the monitor.

\section{Equipment}

Schematic diagrams of the experimental setup and subject's view are shown in Figures 1 and 2. The subject sat $4 \mathrm{~m}$ from the $68.5 \mathrm{~cm}$ (27 in) television monitor that displayed the tracking task. Subjects moved a computer mouse left or right with their left hand to control the driving task. They used their right index finger to press a response button when either brake lamp was energized. Eye position was kept approximately constant across subjects by having them place their chins in a chin rest at a fixed position.

The brake lamps were positioned to either side of the tracking-task monitor such that the visual angle from the center of either lamp to the center of the monitor was $20^{\circ}$. The distance between the lamps and the subject's eye position was $4.26 \mathrm{~m}$. The lamps were mounted on black stands.

Incandescent photoflood lamps were placed on each side of the table to illuminate the face of the brake lamps at approximately 5,500 lx to simulate a daytime condition. Overhead fluorescent lights were also on throughout the experiment. In order to prevent the reflection of these lights from appearing on the television monitor, a baffle made of black board was constructed and placed around the monitor. A matte black cloth covered the wall that was immediately behind the tracking-task monitor and the brake lamps. The resulting background luminance was measured at two locations near the lamps. On the black cloth above the lamps, the luminance was approximately $39 \mathrm{~cd} / \mathrm{m}^{2}$, while on the gray board that surrounded the lamp aperture (see below) the luminance was approximately $63 \mathrm{~cd} / \mathrm{m}^{2}$.

Two computers were used for the study, one to control the onset and offset of the brake lamps and another to control the tracking task. The computer that controlled the lamps also randomized the sequence of lamp presentations, controlled the timing, and recorded the button-press responses. Hardware internal to this computer allowed reaction times to be recorded with millisecond accuracy. Data from the tracking task were not stored. 
Television monitor for the tracking task

Brake lamp visible through an aperture
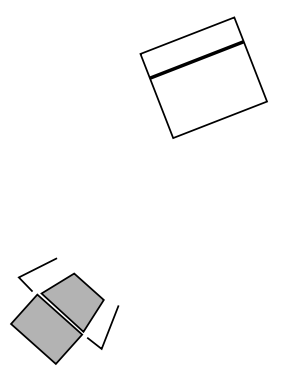

Photoflood lamp

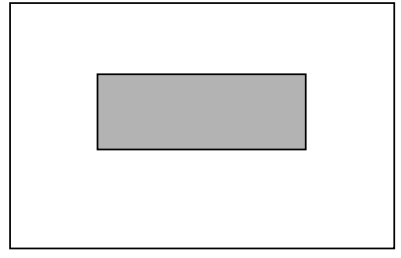

Brake lamp visible through an aperture<smiles>C1C2CC12</smiles>

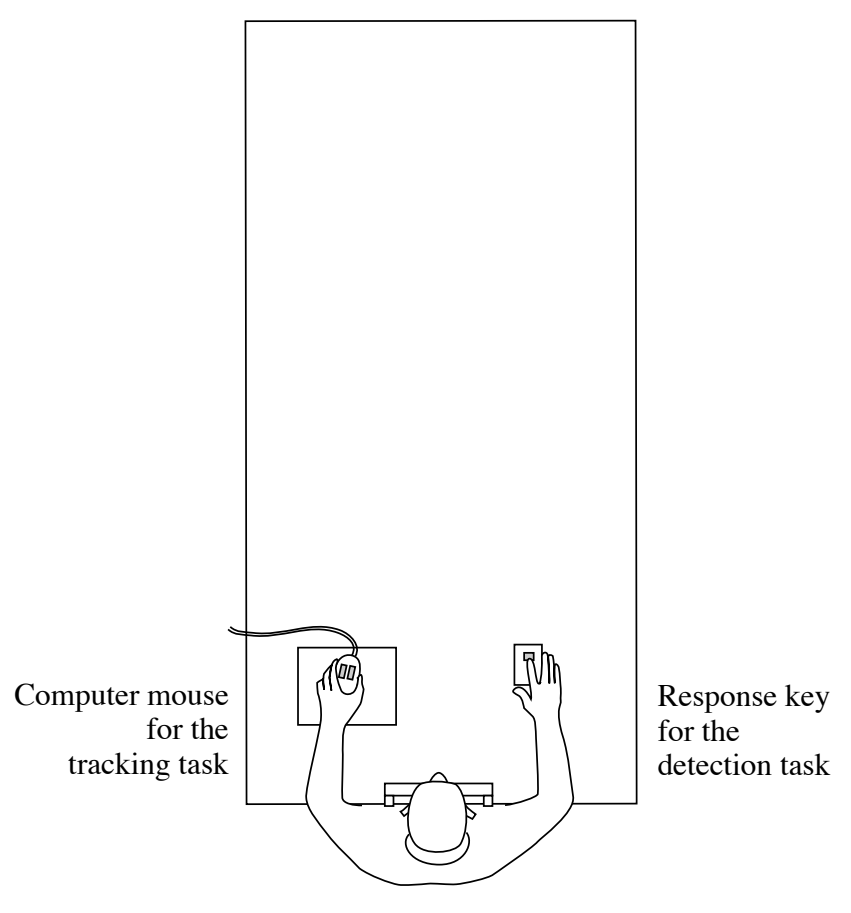

Figure 1. A schematic diagram of the experimental setup. 


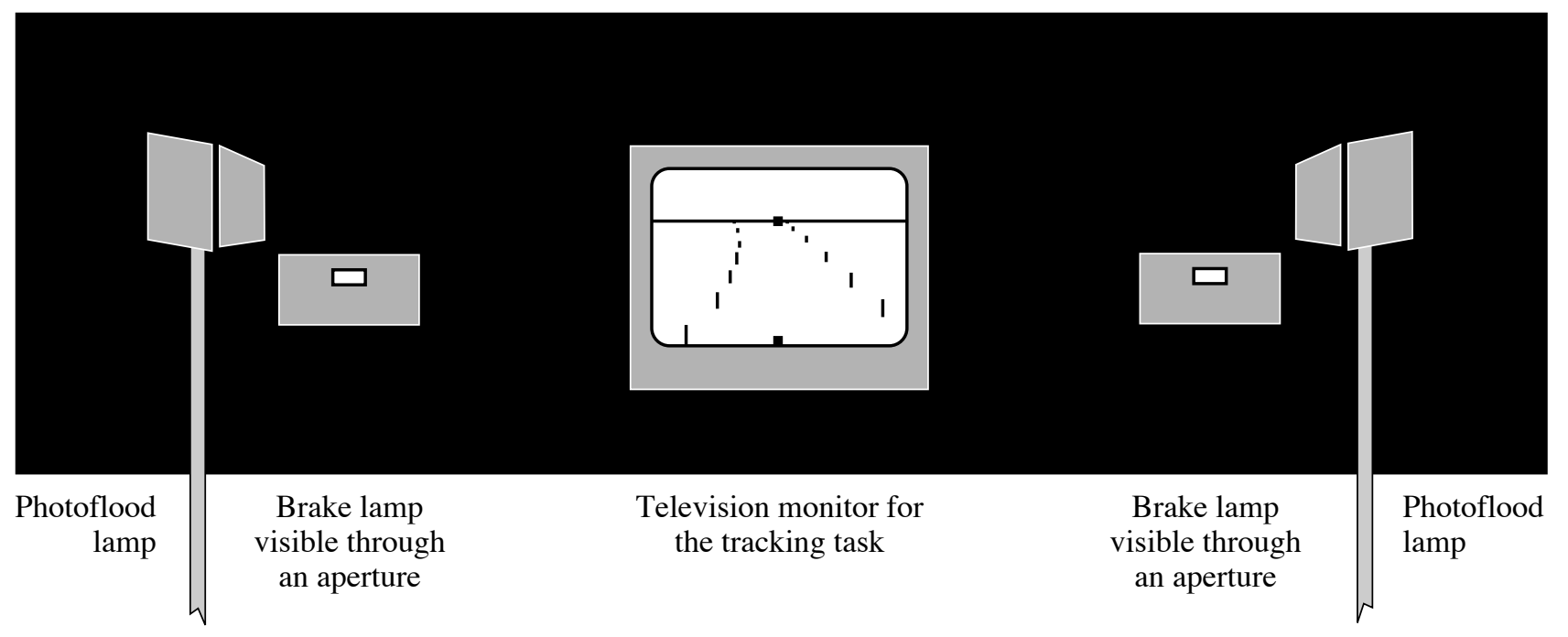

Figure 2. A schematic diagram of the subject's view. 


\section{Brake Lamps}

Four brake lamps were evaluated:

(1) Standard incandescent lamp. A standard incandescent lamp with a \#1157 bulb; the brake filament was used.

(2) Fast incandescent lamp. The above lamp coupled with a device that continuously applies low voltage to the brake filament (keeping it just below visible intensity), and delivers a brief overvoltage at the time of the closure of the switch (Flannagan and Sivak, 1988).

(3) LED lamp.

(4) Neon lamp.

The study simulated the following scenario: brake lamps $16 \mathrm{~cm}$ wide and $4 \mathrm{~cm}$ high (representative of high-mounted brake lamps), luminous intensities of $42 \mathrm{~cd}$ and $5 \mathrm{~cd}$, and a viewing distance of $30 \mathrm{~m}$. To achieve this with the actual viewing distance of $4.26 \mathrm{~m}$, a stiff gray board with a small aperture was placed in front of each lamp. The apertures were $22.8 \mathrm{~mm}$ wide and $5.7 \mathrm{~mm}$ high. Therefore, at the actual viewing distance of $4.26 \mathrm{~m}$, the lamps were effectively $0.31^{\circ}$ wide and $0.08^{\circ}$ high (the same as a lamp $16 \mathrm{~cm}$ wide and $4 \mathrm{~cm}$ high at $30 \mathrm{~m}$ ).

The rise time of the particular neon lamp that was tested was sensitive to the level of ambient illumination. Consequently, the board with the aperture was placed $18 \mathrm{~cm}$ in front of each lamp. This arrangement allowed the ambient illumination to reach the lenses of the lamps.

To produce two levels of luminous intensity, each lamp was tested with and without a neutral density filter in front of the aperture. The filter had a transmittance of approximately $12 \%$. The lamp intensities directed toward the eyepoint of the observers were measured every test day using a Photo Research Pritchard 1980A photometer. The mean effective luminous intensities for the simulated distance of $30 \mathrm{~m}$, averaged over all test days, are shown in Table 1.

Table 1

Mean effective luminous intensity (cd) at the simulated viewing distance of $30 \mathrm{~m}$, by lamp and filter, averaged over all test days.

\begin{tabular}{|l|c|c|}
\hline \multicolumn{1}{|c|}{ Lamp } & Without filter & With filter \\
\hline \hline Standard incandescent & 42.0 & 4.9 \\
\hline Fast incandescent & 42.0 & 4.9 \\
\hline LED & 42.2 & 5.0 \\
\hline Neon & 42.0 & 5.0 \\
\hline
\end{tabular}


Figure 3 shows the light outputs of the four brake lamps as functions of time after the application of voltage. As indicated above, the rise time of the neon lamp that was used in this study was sensitive to the ambient illumination (being longer under low levels of illumination). The rise time shown in Figure 3 applies to the ambient conditions of the present study.

Chromaticity values for each of the lamps in the on state are given in Table 2. All the lamps were within the current U.S. standard of red required for brake lamps (FMVSS, 1991).

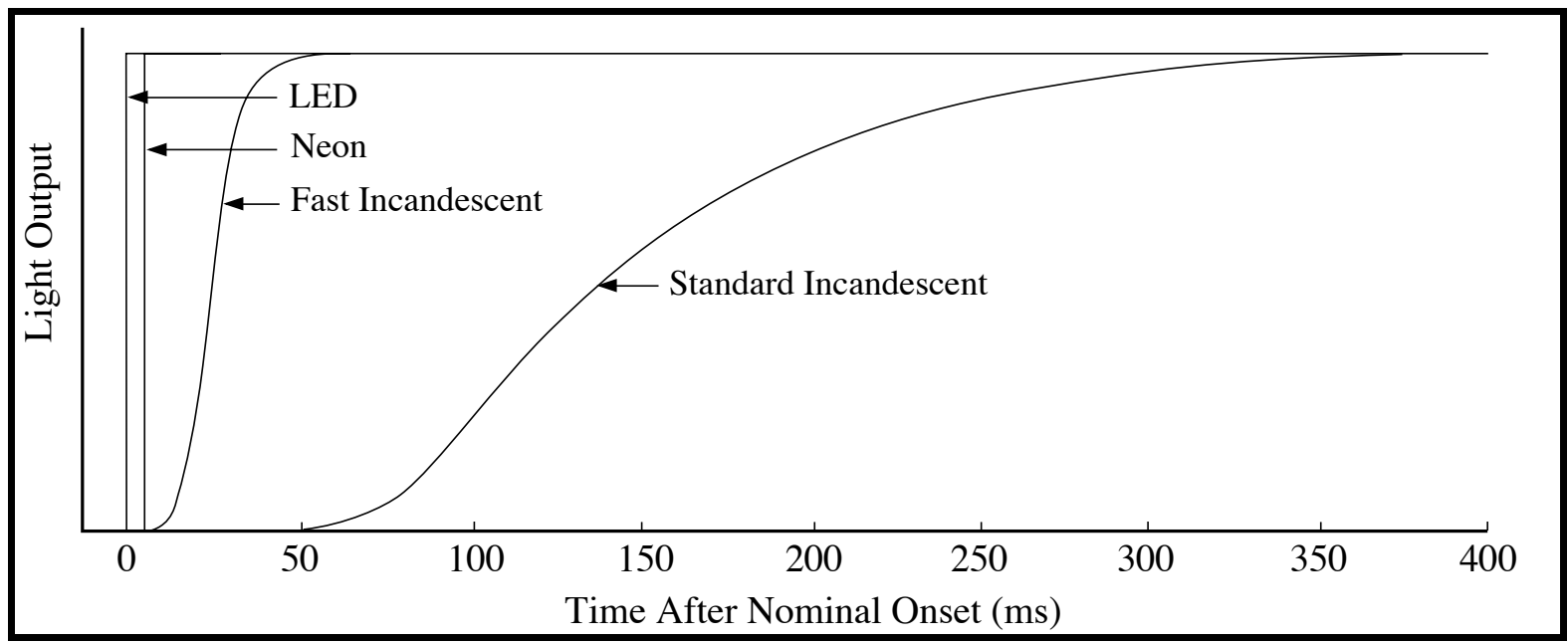

Figure 3. Light output of the brake lamps as a function of time after the application of voltage. (The curves for the standard incandescent and fast incandescent lamps are adapted from Flannagan and Sivak [1989], while those for the LED and neon lamps were obtained in this study.)

Table 2

Chromaticity coordinates of the lamps.

\begin{tabular}{|l|c|c|}
\hline \multicolumn{1}{|c|}{ Lamp } & $x$ & $y$ \\
\hline \hline Standard Incandescent & 0.67 & 0.33 \\
\hline Fast Incandescent & 0.67 & 0.33 \\
\hline LED & 0.73 & 0.27 \\
\hline Neon & 0.67 & 0.33 \\
\hline
\end{tabular}

\section{Subjects}


Sixteen paid subjects participated in the study. Eight subjects were between the ages of 18 and 23 (with a mean of 21), and eight were between the ages of 64 and 77 (with a mean of 70). There were four females and four males in each age group.

\section{Design}

Two of the four lamps were tested during each block of trials. The two lamps were always shown at the same level of luminous intensity. Because there was only one incandescent lamp (used for both the standard and the fast incandescent-lamp conditions), the two incandescent lamps were never paired in the same block. Consequently, the neon and the LED lamps were also never paired in the same block.

The eight combinations of the four lamps and the two levels of luminous intensity were shown to each subject both to the left and to the right of the tracking-task monitor. Within each age-by-sex subject group, each of the eight lamp-by-intensity combinations was presented in each ordinal position of the blocks in the test sequence.

\section{Procedure}

Each subject was tested individually during a one-hour session consisting of nine blocks, including one practice block of 20 trials, and eight test blocks of 20 trials each. The tracking task was explained first, and subjects were allowed to practice until they felt comfortable with it. The reaction time task was then introduced. On each trial, either the left or the right brake lamp was energized. If the subject responded within one second, the lamp was turned off immediately, otherwise the lamp was turned off after one second. Responses longer than three seconds were not recorded; these were considered missed trials and were rerun at the end of the block. There were five lengths of inter-trial intervals: $6,8,10,12$, and 14 seconds. These intervals were randomized, so that the onset of the next lamp appeared unpredictable to the subject. Whether the left or right lamp would be energized on a given trial was also randomized (independently). Short breaks were given between blocks while the experimenter exchanged lamps and/or filters. 


\section{RESULTS}

\section{Parametric analysis}

We performed an analysis of variance for reaction time. The analysis incorporated two within-subject variables, lamp and luminous intensity, and two between-subjects variables, age and sex. The effect of lamp was statistically significant $\left(F_{3}, 36=41.6, p<\right.$ 0.0001). The mean reaction times by lamp are listed in Table 3 and shown in Figure 4. Planned comparisons showed the following statistically significant differences: (1) The neon, LED, and fast incandescent lamps yielded faster reaction times than the standard incandescent lamp. (2) The neon and LED lamps yielded somewhat faster reaction times than the fast incandescent lamp. (The difference between the LED and neon lamps was not statistically significant.)

Table 3

Mean reaction time by lamp.

\begin{tabular}{|l|c|}
\hline \multicolumn{1}{|c|}{ Lamp } & Mean reaction time (ms) \\
\hline \hline Standard incandescent & 662 \\
\hline Fast incandescent & 527 \\
\hline LED & 503 \\
\hline Neon & 489 \\
\hline
\end{tabular}

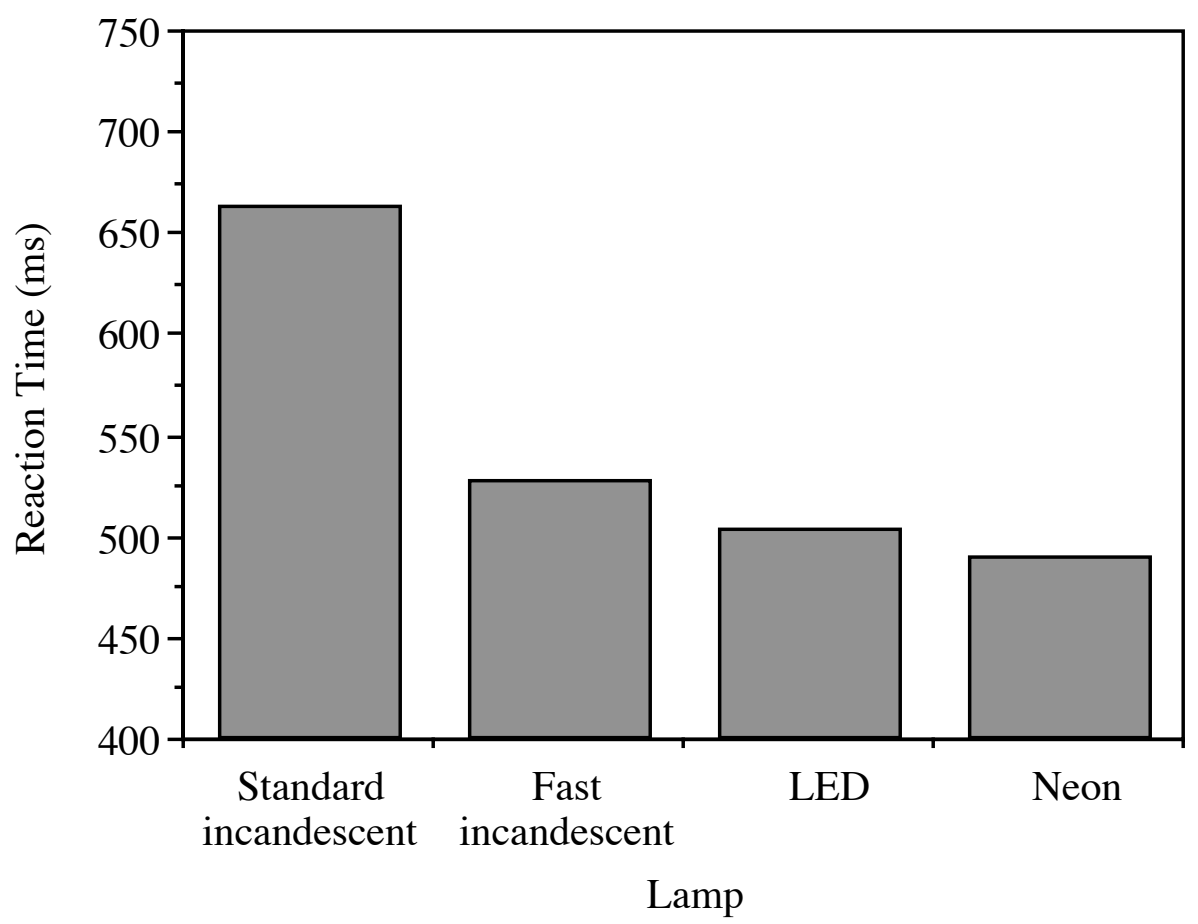

Figure 4. Mean reaction time by lamp. 
The effect of luminous intensity was also statistically significant $\left(F_{1,12}=27.6, p<\right.$ 0.0002). The mean reaction times by luminous intensity are shown in Table 4 . The effects of sex and age of subjects were not statistically significant.

Among all interactions, only two were statistically significant: lamp by luminous intensity $\left(F_{3,36}=3.5, p<0.03\right)$, shown in Figure 5 , and lamp by subject age $\left(F_{3}, 36=3.5, p\right.$ $<0.03$ ), shown in Figure 6.

Table 4

Mean reaction time by luminous intensity.

\begin{tabular}{|c|c|}
\hline Luminous intensity $(\mathrm{cd})$ & Mean reaction time (ms) \\
\hline \hline 42 & 503 \\
\hline 5 & 587 \\
\hline
\end{tabular}


Figure 5. Reaction time by lamp and luminous intensity.

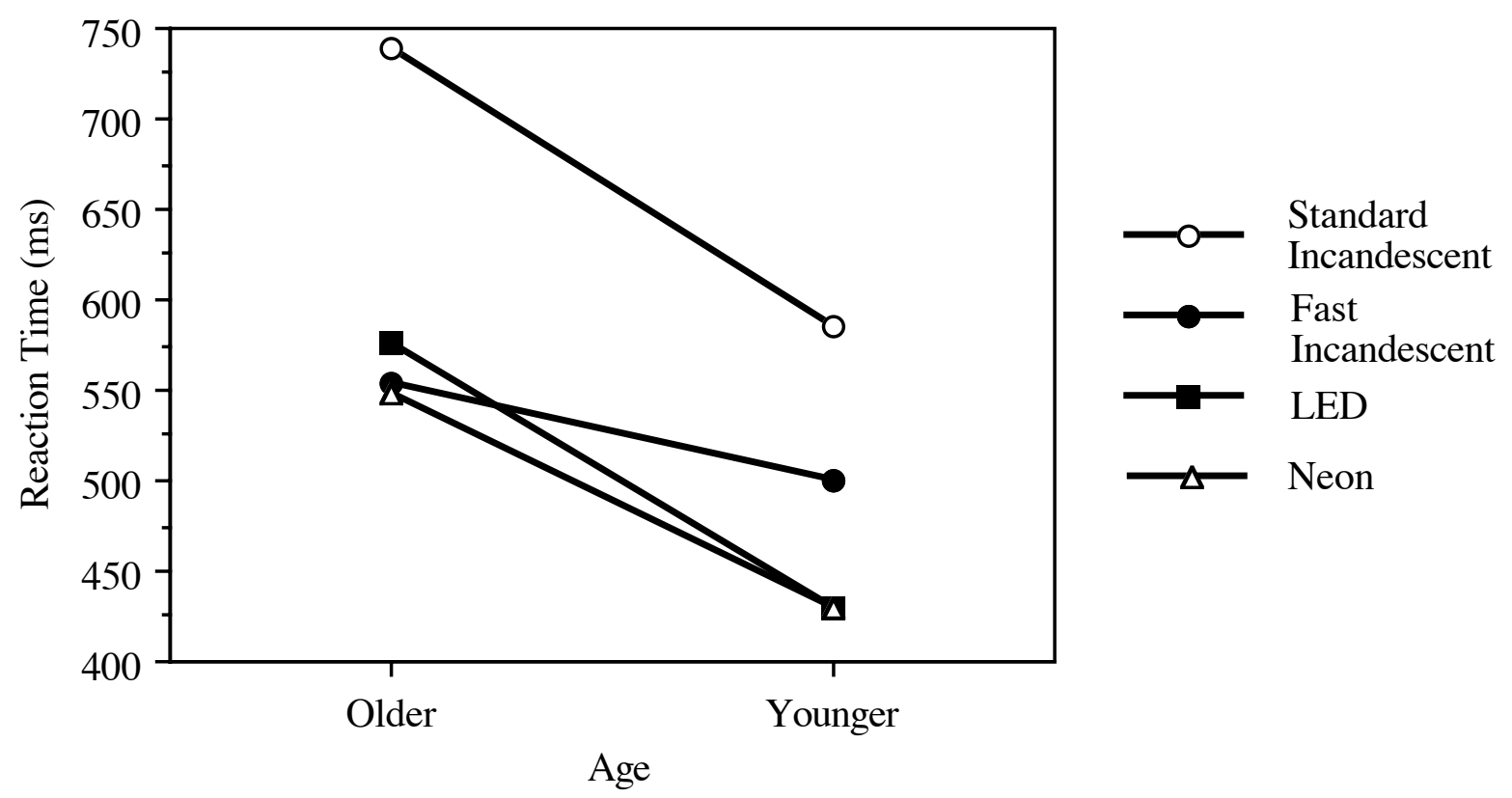

Figure 6. Reaction time by lamp and subject age. 


\section{Nonparametric analysis}

Examination of the distributions of the reaction times revealed that they deviated from normality in being positively skewed (i.e., there were more relatively long reaction times than expected for a normal distribution). Consequently, a nonparametric analysis of the distributions of the reaction times by lamp type and luminous intensity was also performed. Of interest in this analysis was the frequency of very long reaction times. Table 5 lists the percentage of reaction times that were longer than $1 \mathrm{~s}$.

Table 5

Percentage of reaction times that were longer than $1 \mathrm{~s}$.

\begin{tabular}{|l|c|c|}
\hline \multirow{2}{*}{ Lamp } & \multicolumn{2}{c|}{ Luminous intensity } \\
\cline { 2 - 3 } & $42 \mathrm{~cd}$ & $5 \mathrm{~cd}$ \\
\hline \hline Standard incandescent & 8.4 & 13.1 \\
\hline Fast incandescent & 1.9 & 8.4 \\
\hline LED & 3.4 & 9.7 \\
\hline Neon & 2.2 & 8.1 \\
\hline
\end{tabular}




\section{DISCUSSION}

The main finding of this study is that there are several viable alternatives to the standard incandescent brake lamps, all leading to substantially shorter reaction times. The neon, LED, and fast incandescent lamps all yielded shorter reaction times than did the standard incandescent lamp. The fastest reaction times were obtained from both the neon and LED lamps, followed by the fast incandescent lamp. Averaged over both levels of luminous intensity, the difference between the neon and LED lamps, on one hand, and the standard incandescent lamp, on the other hand, averaged $166 \mathrm{~ms}$. Similarly, averaged over both levels of luminous intensity, the difference between the fast incandescent lamp and the standard incandescent lamp was $135 \mathrm{~ms}$.

However, at the lower level of luminous intensity there were no statistically significant differences among the neon, LED, and fast incandescent lamps, and they all yielded shorter reaction times than the standard incandescent lamp (see Figure 5). An analogous pattern was obtained when the data were broken down by lamp and subject age. Specifically, for older subjects there were no statistically significant differences among the neon, LED, and fast incandescent lamps, and they all yielded shorter reaction times than the standard incandescent lamp (see Figure 6). These two interactions suggest that the benefits of the fast incandescent lamp are greater when the amount of light reaching the retina of the observer is reduced, whether by a reduction in the luminous intensity of the signal or by ocular changes associated with advanced age. However, it is not clear why similar interactions are not present for the neon and LED lamps.

There were no statistically significant differences between the reaction times to the neon and LED lamps. Since the rise times of these two lamps under the conditions of the present study were similar (see Figure 3), it is reasonable to infer that their advantage over the standard incandescent lamp is primarily a consequence of their faster rise times.

The rise time of the particular neon lamp tested in this study was sensitive to ambient illumination. However, other neon lamp designs may have rise times that are not sensitive to ambient illumination. Nevertheless, the present findings concerning the neon lamp are applicable only to conditions under which the rise time of the neon lamp in question is similar to the rise time of the neon lamp in Figure 3.

This study evaluated two levels of luminous intensity $-42 \mathrm{~cd}$ and $5 \mathrm{~cd}$. On average, the brake lamps at $5 \mathrm{~cd}$ yielded reaction times that were $84 \mathrm{~ms}$ longer those at the $42 \mathrm{~cd}$. This difference in reaction time was approximately $50 \%$ of the difference between the reaction times to the neon and LED lamps, on one hand, and the standard incandescent lamp, on the other hand. Furthermore, the difference between the reaction times to lamps at $42 \mathrm{~cd}$ and 5 
cd was smaller than the difference between the fast incandescent lamp and the standard incandescent lamp. In other words, under the conditions of the present study, the decreases in rise time from that of the standard incandescent lamp to those of either the fast incandescent, LED, or neon lamps had larger effects on reaction time than an eight-fold change in luminous intensity.

A nonparametric analysis of very long reaction times confirmed the advantage of the neon, LED, and fast incandescent lamps. Specifically, there were substantially fewer reaction times that were longer than $1 \mathrm{~s}$ for the neon, LED, and fast incandescent lamps than for the standard incandescent lamp. Furthermore, for the neon, LED, and fast incandescent lamps at the luminous intensity of $5 \mathrm{~cd}$, the frequencies of the reaction times longer than $1 \mathrm{~s}$ were all similar, and they were comparable to the frequency for the standard incandescent lamp at the luminous intensity of $42 \mathrm{~cd}$ (see Table 5).

How do the present findings compare with previous studies? Olson evaluated reaction times to LED and standard incandescent brake lamps in a variety of conditions (two viewing distances, two levels of ambient illumination, and two angles between the tracking task and the lamp). The advantage of the LED lamps varied from condition to condition, and it averaged $260 \mathrm{~ms}$. A direct comparison between the present results (an advantage of 159 $\mathrm{ms}$ ) and Olson's data is not possible because none of the Olson's conditions was comparable to the one tested in the present study. One possible explanation of the apparently larger effect in Olson's study is that the combination of the tracking and detection tasks was more difficult in Olson's study. In our pilot testing we found a tendency for the advantage of the neon, LED, and fast incandescent lamps over the standard incandescent lamp to increase as the difficulty of the detection task increased. This was the case whether we increased the angle between the tracking task and the detection task, increased the illumination impinging on the lens of the lamp, or decreased the lamp area.

This hypothesis is further supported by the results of Flannagan and Sivak (1989) on fast and standard incandescent lamps. In that study, the advantage of the fast incandescent lamp increased as the difficulty of a secondary task increased. In the most difficult of their conditions (a condition that involved a central tracking task and a peripherally presented lamp) the advantage of the fast incandescent lamp averaged $115 \mathrm{~ms}$, an effect that is comparable to the advantage found in the present study (135 ms). 


\section{REFERENCES}

Flannagan, M.J. and Sivak, M. (1988). Vehicle stop lamp system (U.S. Patent No. 4,791,399). Washington, D.C.: U.S. Patent Office.

Flannagan, M.J. and Sivak, M. (1989). An improved braking indicator (SAE Technical Paper Series No. 890189). Warrendale, PA: Society of Automotive Engineers.

FMVSS (Federal Motor Vehicle Safety Standards). (1991). Standard No. 108. Lamps, reflective devices, and associated equipment. In, Code of federal regulations [Tittle] 49. Washington, D.C.: Office of the Federal Register.

Olson, P.L. (1987). Evaluation of a new LED high-mounted stop lamp. In Vehicle lighting trends (Special Publication SP-692). Warrendale, PA: Society of Automotive Engineers.

Sivak, M. and Flannagan, M.J. (1993). Fast-rise brake lamp as a collision-prevention device. Ergonomics, 36, 391-395. 